Revista Iberoamericana. Vol. LXIV, Núms. 184-185, Julio-Diciembre 1998; 559-571

\title{
EL RETRATO DE UNA ARTISTA JOVEN: LA MUSA DE DELMIRA AGUSTINI
}

\author{
POR \\ Magdalena García Pinto \\ University of Missouri-Columbia
}

\begin{abstract}
Prima en toda su obra la característica
de los [sic] creadores insignes.

Contrariando su sexo, su complexión

de artista y la fortaleza avasalladora de

su espíritu libre y audaz, revelan un

carácter propio solamente de los

varones [sic] de gallardía ilustre.
\end{abstract}

Ovidio Fernández Ríos, La Raza, 14 de agosto 1913

\section{INVENCIÓN DE UN RETRATO}

El retrato de una/un artista es un texto que suscita una serie de interrogantes y curiosidades voyeuristas: el acto de mirarse de un sujeto genera una ficción que fija una imagen inédita. El retrato es asimismo la imagen que la artista proyecta en la imaginación del receptor. Por ello no es casual que este género se haya explorado tanto en la literatura como en las artes plásticas, en las que el género del autorretrato ha provocado una constante fascinación entre espectadores, lectores y críticos. En algunos casos, la composición del retrato incluye elementos que generan cierta intriga. Un caso clásico es el autorretrato de Vicent Van Gogh con la cabeza vendada. El torturado artista deja la marca de su desesperación en el espacio blanco que cubre parte del rostro. Entre los retratos de artistas mujeres, se destaca el de Elisabeth Vigée-LeBrun con la paleta en la mano. Tal vez la artista que ha transformado la estética del autorretrato al postularlo como el tema central de sus telas es Frida Kahlo. La tematización de su circunstancia, desafiando al espectador de manera frontal, ha logrado generar una inacabable curiosidad tanto en el gran público como en la crítica cultural.

El retrato plantea el interrogante acerca de la relación de la artista con el material literario, que en la poesía lírica está mínimamente mediatizada. El autorretrato apela tanto al narcisismo como a la curiosidad voyeurista que sugiere el acto de desenmascaramiento del sujeto. Entre los retratos literarios, Portrait of an Artist as a Young Man (1916) de James Joyce ha despertado considerable atención y es el que me sugirió la posibilidad de explorar cuáles fueron los vehículos discursivos a los que Agustini recurrió para crear una imagen de sí, y cuáles fueron los dispositivos a los que apeló para poner en escena esta autorrepresentación. 
El retrato no sólo abre una brecha por la cual se puede entrar a los intersticios de la intimidad de una artista, sino que también requiere la elaboración de una modalidad discursiva que le permita ponerse ella misma en la escena escritural. El autorretrato me interesa además porque parece establecer una diferencia genérico-sexual en su procedimiento.

La intención y posiblemente la necesidad de Delmira Agustini de construir un retrato que la representara como artista en su etapa de formación y desarrollo, en el cual pudiera reconocerse y afirmarse como sujeto es el tema de este trabajo.

Cuando Delmira Agustini murió prematuramente a los veintisiete años, ya había alcanzado el renombre de poeta excepcional y el título de gran poetisa (sic), la más grande de América. Por ello, la construcción de su persona pública ofrece un escenario particular para examinar los complicados términos de la política sexual que se desprenden de la fascinación ejercida por esta poeta joven de talento en la imaginación masculina de principios de siglo. En palabras de Clara Silva:

Delmira Agustini es, sin duda, la figura más problemática de la literatura uruguaya; y probablemente de la poesía hispanoamericana. No en cuanto a los valores de su poesía misma, ya reconocidos unánimamente por la crítica, entre los más altos de la lírica de nuestra lengua, sino en cuanto a la personalidad de la poetisa (sic) (7).

Los dos estudios de Clara Silva son, sin duda, de gran valor para el conocimiento de la vida y obra de la poeta en tanto continuó la investigación iniciada por Ofelia Machado en la recopilación de documentos. En los años que dedicó a estudiar a Delmira Agustini, Clara Silva pudo localizar nueva información que se complementa con el testimonio que pudo recoger de la gente que conoció a Agustini. Debemos suponer que en el proceso de su investigación, Clara Silva tuvo conversaciones importantes con su marido, Alberto Zum Felde, para dar forma a su estudio sobre Agustini. Zum Felde, destacado intelectual del Uruguay de este siglo, dos años menor que Delmira, conoció y fue amigo de la poeta durante el último año de su vida.

Para reconstruir este doble proceso, he tenido en cuenta por un lado, testimonios personales, comentarios y otros escritos que aparecieron durante la trayectoria literaria de Agustini, y por otro, los que proliferaron a raíz del asesinato a manos de su ex-marido, Enrique Job Reyes. La trayectoria de vida, y más aún su muerte, alimentaron como pocos acontecimientos hasta la fecha, la imaginación de los letrados uruguayos a lo largo del siglo veinte. Las publicaciones sobre Delmira Agustini dan cuenta de estos datos, cuya interpretación ofrece al lector considerable variación. En este trabajo, me referiré a algunas de estas versiones que proveen un punto de partida para examinar tanto la visión del otro como los dispositivos que Agustini incorpora a su sistema poético para construir su retrato simbólico de artista finisecular en tiempos simultáneamente excitantes y difíciles para las artistas rioplatenses.

Delmira Agustini fue, no cabe duda, una figura célebre en sus días, los primeros años de aquel novísimo siglo veinte. Fue recibida con grandes alabanzas por los letrados uruguayos desde el momento en que presentó sus primeros poemas al público montevideano, y tuvo la oportunidad de publicar sus poemas desde el comienzo de su carrera literaria (Ver García Pinto, "Los letrados uruguayos", "La crítica hispanoamericana" y "Ensayo introductorio"). La complejidad con que su medio construyó su persona pública se debe en 
parte a aspectos de su persona que fueron juzgados como fuera de la norma, al tiempo que fueron la razón por la que ella alcanzó gran notoriedad entre el círculo de relaciones masculinas con el que se comunicaba y en el que tangencialmente actuaba. Sus contemporáneos, embelesados por la energía erótica que sentían emerger de los poemas de esta joven, respondieron con efusividad a los vuelos de la imaginación, construyendo una serie de imágenes que dejan transparentar la ambigüedad con que Delmira Agustini fue considerada por los letrados de su tiempo.

A pesar de esta temprana recepción y fama, la poeta vivió en una marginalidad real, similar a la de otras escritoras de su tiempo. Siguiendo una práctica bastante difundida entre las clases acomodadas, recibió su instrucción escolar en su hogar y en un colegio de monjas; ${ }^{1}$ posteriormente estudió piano y pintura con maestros particulares. En el taller de pintura conoció a André Giot de Badet, probablemente la persona con quien la poeta tuvo mayor amistad y a quien ella confió su intimidad. Tal vez fue el relativo aislamiento en el que vivía, el que la hizo mantener una amplia correspondencia con sus contemporáneos en América Latina. Su trayectoria de poeta joven comenzó en 1902 cuando se publicó su primer poema en la revista La Alborada, donde pronto le asignaron una sección titulada "La Legión Etérea" destinada a construir retratos de un grupo de mujeres prominentes de Montevideo. Este es una primera en el desarrollo de este dispositivo de representación. Fue amiga de María Eugenia Vaz Ferreira, de quien escribió una de estas semblanzas, y fue muy admirada por Gabriela Mistral y Alfonsina Storni. La publicación de sus poemas en revistas y la publicación de sus poemarios continuó sin interrupciones hasta 1914, fecha de su muerte (García Pinto, "Los letrados uruguayos").

A pesar de haber sido tan ensalzada y admirada, no participó en los círculos literarios de su época. No hay certeza de que haya tenido diálogo con Julio Herrera y Reissig en una ciudad tan pequeña como el Montevideo de principios de siglo, si bien en el Archivo Delmira Agustini de Montevideo existe una breve misiva del poeta a Delmira a raíz de la publicación de uno de sus poemarios. Por su parte, ella le dedicó un poema a Julieta de la Fuente, la mujer de Julio Herrera, titulado "El dios duerme", publicado en 1914 en ocasión de la muerte del vate. El poeta Sabat Ercasty, en una entrevista de 1981, cuenta que había conocido a Delmira en casa de Julio Herrera ("Delmira y su mundo").

Este reconocimiento tenue de su arte se afianza considerablemente cuando Rubén Darío, en su paso por Montevideo en 1912, dejó registrada su admiración por los poemas de Delmira en el sentido de que genera una actitud más seria hacia su obra por parte de sus contemporáneos. ¿Debemos interpretar que al considerarse "apadrinada", las figuras de talento comienzan a escribir sobre ella? El hecho es que Alberto Zum Felde, Roberto de las Carreras, Manuel Ugarte, entre muchos otros, comienzan a anotar las novedades que aporta la poesía de Agustini. No obstante, los letrados principalmente la admiran como una joven atrevida y bella mujer, al tiempo que otros hallan oportuno cortejarla pues se sienten atraídos más por la poeta que por su poesía.

Un ejemplo del estilo epocal y de la admiración que provocó es la "Carta abierta" fechada a principios de 1913 de Alberto Zum Felde, en la que da cuenta del descubrimiento de un valor nuevo en los siguientes términos:

${ }^{1}$ Aunque todos los biógrafos de Agustini han señalado que no asistió a ninguna escuela, Bula Piriz anota que Delmira asistió al Colegio del Huerto de Montevideo. 
Pero lo que os diferencia de cuantas, antes que vos, hayan cantado su amor es que ellas lo hacían solicitadas por una pasión personal, enardecidas por un hombre, por ese amor; y vos, sentís el amor "en esencia", el deseo "en sí mismo", y el amante "como entidad". Vos sois el amor mismo. Eros arde, con llama perenne dentro de vos, tornándoos flamígera. Vuestro erotismo arde y se consume en su propia llama. Así estáis hecha para el Arte ("A Delmira Agustini. Carta Abierta").

La exaltación de Zum Felde se transforma en más que impertinencia en las cartas de Roberto de las Carreras y algunos otros con quienes Delmira tuvo correspondencia. Curiosamente, esta sexualización temprana de la poeta continuó persistentemente en el discurso de los letrados a lo largo de este siglo. Baste como ejemplo una cita de Emir Rodríguez Monegal en un brevísimo estudio sobre la poeta en la que dice:

A su manera, también Delmira escandalizó a la aldea [...] y paseó sus arrebatos de pitonisa en celo, de hembra ardida, por las páginas de libros que se iban poniendo más y más incandescentes a medida que la autora (joven pero no niña) libraba poéticamente sus combates (8).

La atracción finisecular que Delmira Agustini continúa ejerciendo sobre el público ríoplatense reaparece en la ficción narrativa actual, cuando ya se han cumplido más de cien años de su nacimiento. A partir de la novelita titulada, Una mujer inmolada ..., que Vicente Salaverri publicara en 1944, la vida, los imaginados amores de la poeta y los momentos previos a su asesinato han inspirado versiones teatrales y un ballet representados en Montevideo. Más recientemente, como muestra del interés que sigue despertando, Pedro Orgambide escribió una novela titulada Un amor imprudente (1994), Omar Prego Gadea, un texto en el que combina la ficción y documental titulado Delmira (1996) y Guillermo Giucci, Fiera de amor: la otra muerte de Delmira Agustini (1995). La crítica, por su parte, ha publicado una colección de ensayos con el inacertado título de Nuevas penetraciones críticas, editada por Uruguay Cortazzo, quien explica su mala conciencia de esta manera:

[...] quisiera dejar en claro que el título de esta selección es pura y exclusivamente de responsabilidad mía y no compromete a los otros investigadores. Tampoco a la editorial, salvo en el hecho de que no insistiera más para que lo modificara. Gracias Damyán (Cortazzo 9).

Estos y otros testimonios de los letrados uruguayos e hispanoamericanos construyeron una figura de mujer atrapada en una sexualidad que, en general, obstaculizó la claridad de la investigación que dio como resultado estudios muy fragmentarios.

\section{Mujer y artista en Montevideo 1900}

Conviene recordar que a inicios del siglo veinte, la sociedad rioplatense vivió intensamente el rápido proceso de modernización, que impactó de manera bastante compleja las relaciones genérico-sexuales de la sociedad. ${ }^{2}$ Si por un lado grupos de mujeres

${ }^{2}$ La literatura sobre la modernización en el Río de la Plata es abundante. Remito al lector en particular a los trabajos de Ángel Rama, Francine Masiello, Julio Ramos, Beatriz Sarlo, Hugo Achugar y 
de las clases medias de Buenos Aires y Montevideo comenzaron a participar y a hacer oír sus reclamos sobre la igualdad de derechos y de justicia social, por otro, dichos movimientos socio-políticos lograron modificar tan sólo parcialmente la visión de mundoy la función que la cultura masculina asignaba a las mujeres de clase burguesa, el de ocupar un lugar privilegiado, el de estar "protegida" del asedio del otro y en particular de sí misma, mediante la apelación a recursos que resultaron en confinamientos de diversa índole. Modelizadas bajo la intersección de una ideología de clase y género, estas estrategias remitieron a las mujeres de la alta y media burguesía a los confines de la casa paterna, de la cual era imposible salir sin la aprobación del pater familias, y tan sólo con el fin de constituir un nuevo núcleo familiar, bajo la tutela del marido. Las no casaderas quedaban en el corazón del espacio patriarcal para cuidar a los padres y atenderlos hasta que les llegara la muerte. La misión fundamental de la mujer, incumplida al no haberse casado, encontraba un canal de desahogo en el espacio privado, en las tareas domésticas y en el espacio público, en las iglesias; de allí el dicho "se quedó para vestir santos". Es decir que para aquellas que no habían encontrado una misión en la vida, la circulación en el espacio público estaba circunscrita al espacio íntimo de la casa, el de los jardines y huertas interiores y, ocasionalmente, a ayudar en las tareas del culto eclesiástico. Las mujeres eran propiedad del patriarcado - padres, maridos, eclesiásticos-, y de ellas disponían.

La severidad con que se cercaba la vida de las mujeres está íntimamente conectada al concepto de corrupción del linaje, sobre el que Francine Masiello ha apuntado que

[E]n la medida en que cada vez más las mujeres ocupaban la intersección entre las actividades públicas y privadas, también se las consideraba responsables de contaminar la esfera pública y de corromper la familia (188).

¿De qué manera la contaminación y corrupción son pertinentes para estudiar la interacción de las mujeres escritoras y artistas con su medio cultural? Bram Dijskstra en su estudio Idols of Perversity (1986) señala que tener relaciones con una mujer sexual era equivalente a la muerte misma ("to get involved with a sexual woman was equivalent to death itself"). Delmira personificaba una serie de riesgos, por lo cual no es excesivo proponer que su figura fue vista como posible fuente de contaminación de la sociedad burguesa. Representaba, sin duda, un cambio en los parámetros con que se medía y juzgaba el comportamiento de las mujeres, según se desprende de los diversos comentarios sobre su persona y su poesía.

Su apariencia física era juzgada como muy llamativa; su pelo, sus ojos y su atuendo, particularmente cuando llevaba un famoso traje y sombrero rojos provocaron más de una reacción. La frase citada de Dijsktra nos permite proyectar un doble sentido, aplicable tanto a Enrique Job Reyes como a la poeta, al tiempo que revela la atracción que ésta ejerce entre los hombres que la asedian, ya sean contemporáneos suyos o sus lectores actuales.

No dudo que el asesinato de la poeta está alimentado por el sentido y la necesidad de posesión que Reyes se atribuía por derecho matrimonial, aun cuando dicho lazo ya se había disuelto. No quiso aceptar, y no aceptó, la disolución que por ley le concedía a Delmira

Josefina Ludmer. En particular ver Masiello: “Tercera Parte. La Modernidad y la restauración nacionalista". 
disponer sobre su propia persona. Esta percepción era tan profunda que terminó con la única e irreversible solución demandada por el orgullo masculino, la de poner fin a la discordia con la muerte.

\section{El retrato en Clave De mujer como artista}

Se solía pensar y hasta se probó "científicamente" que una mujer no podía verdaderamente ser una artista, pues no poseía las facultades creativas necesarias para elaborar una obra original digna de ingresar en el panteón de los Grandes Poetas; el don de la creación no le había sido concedido por la naturaleza, por lo tanto dicha artista era considerada un ser fuera de lo normal.

A las mujeres les incumbía el alterar esta práctica. Las artistas necesitaban crear un espacio a través y en el cual hacerse presentes en el mundo del arte. El proyecto poético de Delmira, según señalamos arriba, había generado una situación de agitación, inquietud e incertidumbre en torno a ella. ¿Cómo tratarla? ¿Cómo relacionarse con ella, como mujer o como poeta? Y si bien se la consideraba una gran poeta, de todos modos los temas de sus poemas generaban inestabilidad entre sus lectores y lectoras, e incertidumbre acerca de cómo interpretar su poesía. Todos sus contemporáneos que la elogiaron sin recortes se preguntaron lo mismo: ¿cómo es posible que esta jovencita inocente y sin experiencia sexual escribiera poemas de tan cargado erotismo? La respuesta era que estaban ante un enigma, un misterio. No podían concebir otra explicación. No la imaginaron de otro modo mientras vivió. Después de muerta, dos décadas después, Zum Felde escribió su interpretación sobre el misterio poético que Agustini representaba, y dicha interpretación marcó profundamente la crítica uruguaya hasta comienzos de los noventa (Ver Uruguay Cortazzo, "Una hermenéutica machista").

No era tan sólo el proyecto poético de Agustini el que estaba en cuestión. El otro aspecto definitorio en su vida está conectado con la percepción de su visión de mundo y de actuación. Aunque siguió las costumbres de la época, lo hizo desafiando los dictámenes de la moral burguesa: no se casó a la edad debida, es decir, permaneció soltera demasiado tiempo, y cuando finalmente se casó a los veintiséis años, sólo fue esposa muy poco tiempo - cuarenta días - al cabo de las cuales, hizo abandono del hogar. Se negó a ser la mujer de un hombre burgués y a ser madre. Ambas situaciones fueron percibidas como transgresoras y provocaron reacciones de una impertinencia notable. Su posterior divorcio contribuyó a aumentar indiscreciones masculinas. Los hombres interpretaron la separación y el proceso de divorcio como licencia para hacerle proposiciones que aún hoy sorprenden.

Pero antes de llegar a este trágico final, la poeta debió haberse preguntado ¿Qué hacer ante las restricciones sociales que tan profundamente afectaban el comportamiento femenino y su destino humano? Cada poeta finisecular tuvo que enfrentar esta cuestión genérica, y cada una de ellas ofrece algunas "tretas del débil" (Ludmer). La naturaleza oximorónica de esta estrategia se combina con la creatividad que genera la resistencia del subalterno, recursos ambos que más que tretas, constituyen a mi parecer dispositivos poéticos femeninos que subrayan la creatividad y destreza en adaptar los requisitos canónicos a la situación en la que se encuentran. 
Otra implicación importante de estas construcciones de la persona pública Delmira Agustini por parte de los letrados hispanoamericanos es que expone de manera casi dramática el gran vacío de precursoras en la genealogía de las letras femeninas de inicios de siglo. De manera paradójica, una literatura femenina en proceso de formación, marcada por esta falta en el camino de la creación, sitúa a Delmira Agustini en el papel de fundadora de una poesía femenina inédita.

Agustini conocía profundamente la obra de los poetas modernistas hispanoamericanos, en particular la de Rubén Darío; también había leído a los poetas simbolistas franceses con su amigo André Giot de Badet. Es así que a partir del paradigma poético modernista, del cual toma lo que le es necesario para elaborar sus temas e iniciar su trayectoria literaria, y posteriormente, habiendo logrado gran maestría en dicha práctica, Agustini escoge el material con que elabora sus temas en los que la voz lírica y la poeta puedan identificarse sin abandonar las convenciones de la estética dentro de la cual escribe. Este procedimiento caracteriza su poética, particularmente, en el modo de construir o reconstruir ciertos personajes modernistas. Es así que el panorama de la vida pública y privada de Agustini que hemos delineado contrasta marcadamente con la visión que la poeta creó a través de la construcción de figuras simbólicas utilizadas como un vehículo eficaz de expresión.

Las dos figuras femeninas que enfoca esta investigación son la Musa y la Estatua, a las que se les asigna una doble función, la de servir de guía de su trayectoria creativa y la de proveer de una máscara que encubra y revele una voz inédita. Estas son figuraciones de una misma representación, ser imaginario con el que el sujeto lírico se identifica y a los cuales apela e interroga para proyectarse en ellos. Son recurrentes en los poemas de su primer libro El Libro Blanco (Frágil), y en algunos son el leit-motif. La poeta joven recurre a esta simbología para inventar una identidad que luego irá transformándose en poemas posteriores.

En la literatura occidental la musa representa un ideal abstracto de mujer, objeto de la mirada y admiración masculinas y pertenece a la tradición de ser invocada por los poetas para que los ilumine ("Canta, Oh diosa, la ira del Pelida Aquiles", dice el primer verso de La Iliada) práctica en vigencia durante el Modernismo. A veces, esta misma práctica retórica identificaba a la amada con la musa inspiradora entre los poetas.

Sin embargo, a partir de su primer libro de poemas, estas dos figuraciones acompañan, doblan o se identifican con el sujeto lírico. El Libro Blanco (Frágil) de 1907, despliega a partir del primer poema este proceso de construcción de la figura de la musa. Aparece inicialmente en el papel romántico de poseedora y transmisora de una fuerza imaginaria e iluminadora que guía y acompaña a la poeta en la búsqueda de la perfección lírica. Con su doble, la voz lírica se lanza a la aventura de la creación:

Partamos, musa mía!

Ante la prora alegre un bello mar se extiende.

("El poeta leva el ancla")

A pesar de entrever el horizonte despejado por una visión optimista, el poema concluye con una interrogación sobre lo que vendrá en textos posteriores: 
... acaso

Sueño lo que me aguarda en los mundos no vistos?

Las posibilidades imaginadas en la trayectoria son símbolos de nobleza que se contraponen a una primera visión del fracaso:

Acaso un fresco ramo de laureles fragantes,

El toisón reluciente, el cetro de diamantes,

El naufragio o la eterna corona de los Cristos?...

("El poeta leva el ancla")

En el poema "La musa", Agustini extiende la complejidad semántica de esta figura al dotarla de una función adicional para extender los niveles de expansión del campo significativo y así exponer en la escena de la escritura, los obstáculos para una artista de su tiempo:

Yo la quiero cambiante, misteriosa y compleja;

Con dos ojos de abismos que se vuelvan fanales,

En su boca, una fruta perfumada y bermeja

Que destile más miel que los rubios panales;

Y que vibre, y desmaye, y llore, y ruja, y cante,

Y sea águila, tigre, paloma en un instante,

Que el Universo quepa en sus ansias divinas;

Tenga una voz que hiele, que suspenda, que inflame,

$\mathrm{Y}$ una frente que erguida su corona reclame

De rosas, de diamantes, de estrellas o de espinas! ("La musa")

En esta figuración, los atributos enumerados reemplazan la imagen pasiva de la musa masculina: cambiante, compleja, etc. La mirada de la musa, ligada a la imagen de la estatua en otros poemas, transforma los "ojos de abismo" en "fanales que iluminan el camino". La confluencia de contrarios son imprescindibles para lograr elevar el reclamo que para sí demanda, el ser reconocida como poeta.

Retoma el mismo tema en los poemas "La musa gris", "Mi oración", un poema sin título cuyo primer verso dice "Mi musa tomó un día la placentera ruta", "Visión de otoño", "La agonía de un sueño", "Mi musa triste" y "Misterio, ven". En "La musa gris", eco de "Sinfonía en gris mayor" de Darío en su concepción monocromática, la musa es una figura de blancura de cirio, ojeras grises, perfume de tristes violetas, cabellos de sombra, mirada de vidente, cuyo poder de visionaria de "mirada invencible de esfinge y estatua" desconcierta a su público; es también "la musa que canta blancuras opacas, / Y el gris que es el fondo del hombre y la vida". El enigma y el misterio, conceptos muy preciados por los modernistas, son aquí los atributos para crear una figura de poeta que sea admirable e inalcanzable. El monocromatismo del poema anterior, retorna en "Visión de otoño", donde una silueta no nombrada de ojos grises, que se desliza como "una ráfaga de un frío de ultratierra", prolonga 
la visión anterior con un pronunciado tono ominoso. Nótese que no es "ultratumba", sino su contrario, expresado con una palabra creada.

En "La agonía del sueño", poema largo de once estrofas de cuatro versos largos, la musa llora, vencida por el dolor que producen las visiones sombrías que interrumpen la creación poética. Siente desmoronarse aquel horizonte de posibilidades entrevisto en el sueño del primer poema, "El poeta leva el ancla", citado arriba. En este marco de referencia, la voz lírica pregunta:

Nunca habéis visto agonizar un sueño?

Un noble sueño que llenó la vida?...

Al borde de la caída, sin embargo, la intimación al llanto del primer verso, "Llora, mi musa, llora en silencio", es revertido con intensa determinación, en la última estrofa:

Ah no, no lloro más! Pase el Destino,
Pase el dolor del brazo de la Muerte,
Les miraré pasar desde mis torres
Con una calma atroz que desconcierte!

Este movimiento de sentimientos encontrados expresados en primera y tercera persona, se intensifica en la musa cuyos ojos grises se han tornado en los ojos de ámbar de "Mi musa triste". Este atributo que representa la energía psíquica del alma es nombrado para dramatizar la visión proyectada en los poemas anteriores:

Horizontes violados sus ojeras

Dentro, sus ojos - dos estrellas de ámbar-

Se abren cansados y húmedos y tristes

Como llagas de luz que se quejaran.

Es un dolor que vive y que no espera.

Y sus canciones son como hadas tristes

Alhajadas de lágrimas ......

El poema concluye equiparando la centralidad de las palabras con el proceso creador:

Las cuerdas de las liras

Son fibras de las almas.-

En estos poemas de El Libro Blanco (Frágil) hemos visto que Agustini no solamente construye una imagen romántica de poeta joven en la figura de la musa, sino que también por su intermedio asigna a la forma del poema menos valor que al concepto que expresa y a la visión que proyecta. Es, decir, se arriesga a rechazar el artificio formal modernista en un momento en que la belleza de la forma, de los ritmos elegantes y rimas novedosas de Darío y de Herrera y Reissig han dotado a esta estética de gran prestigio y extraordinaria 
destreza creativa. Su postura abiertamente enunciada en desfavor de estos procedimientos es una manera de afirmarse como poeta con una visión independiente.

Sabemos que Darío incorporó al material poético modernista los motivos de las fiestas galantes del barroco francés. En la transposición plástica de dichas escenas, aparecen en el jardín del amor unas estatuas cuya función es complementar el tema central de la pintura por medio de la representación de una historia contenida en el diseño formal de las estatuas. En la transposición de la estatua al material poético, el ámbito de las estatuas verbales repite o cita los jardines y palacios dieciochescos, con sus espacios de artificio apropiados o inspirados por la imaginería pictórica de Watteau y los artistas de les fêtes galantes dedicadas al culto de Venus. Los textos paradigmáticos del modernismo hispanoamericano "Era un aire suave..." y "Sonatina", ambos de Prosas profanas (1896), son emblemáticos de este proceso de transposición. La musa es complementada por la figura de la estatua, como apuntamos arriba. Manuel Alvar fue el primero en anotar la importancia de esta figura en Agustini y en tratar de dilucidar su significado:

Son las estatuas, encarnación del dolor íntimo, y son las serpientes, trasunto de los deseos. Creo que se puede entrar con alguna seguridad en este mundo alegórico. La estatua ofrece una acabada perfección, pero en la frialdad hermosa del mármol está la angustia violenta de su falta de humanidad. Por eso la plenitud de la estatua es dulcemente triste, como lo es el alma de la poetisa (sic); por eso en los momentos más serenamente dolorosos de Agustini asoma la blancura de la piedra esculpida:

Mas fría que el marmóreo cadáver de una estatua,

Miré rodar espinas, flores, diamantes,

Como el bagaje espléndido de una Quimera fatua.

("Las coronas", Cantos de la mañana)

Por eso la total identificación - ya no comparativa - de la mujer con la fría materia y por eso la emocionada plegaria ansiosa de dar humanidad a la perfección artística:

¡Dios!... ¡Moved ese cuerpo, dadle un alma!

Ved la grandeza que en su forma duerme...

Vedlo allá arriba, miserable, inerme,

Mas pobre que un gusano, siempre en calma!

("La estatua", en El libro blanco), (Alvar 49-50)

Si bien concuerdo con Alvar en la importancia simbólica de las estatuas, no lo estoy con su interpretación de su función en este sistema poético, cuyo valor significativo, como venimos apuntando, le abre a la poeta nuevas posibilidades expresivas. La estatua, como la musa, se integra a los poemas con una función que va más allá de la decoración o complementación del tema central. La inmovilidad y el blanco del mármol son los atributos de esta máscara que encubre la persona poética en ciernes ("Ved la grandeza que en su forma duerme"). La novedad de esta investidura es doblar la voz del sujeto lírico. El carácter ornamental y la estructuración simbólica de las estatuas de mármol oculta la potencialidad vital de la metamorfosis inscripta en la figura del mito de Pigmalión y Galatea. En el poema "La estatua" la hablante lírica marca el contraste del emplazamiento de la figura contra el verdor del parque y con admiración se interrroga: 
Miradla, así, sobre el follaje oscuro

Recortar la silueta soberana

¿No parece el retoño prematuro

De una gran raza que será mañana?

¿De quién habla? ¿Quiénes constituyen esta "gran raza”? El esfuerzo de la visión de la voz lírica entreve la posibilidad sólo forjada en el taller de la artista:

Así una raza inconmovible, sana,

Tallada a golpes sobre mármol duro

El retoño es la procreación de la facultad artística cuya obsesión y fin es la belleza misma. Esta raza nueva representada por la recién concebida Galatea, desalojará a la familia humana. Será, parece implicar la voz lírica, más perfecta:

Dios ... moved ese cuerpo, dadle un alma

Ved la grandeza que en su forma duerme...

Bajo la egregia forma, vive y quiere emerger, irrumpir, la grandeza del alma.

Esta conceptualización de la estatua le permite a la poeta potencializar el valor del símbolo clásico, bello, perfecto, pero también mudo y frío, a través de la visualización de sus posibilidades: hay detrás de esa forma una mujer que traerá una nueva vida, una nueva raza, la de la artista, esa que está oculta, contenida e imaginada en la aparente frialdad del mármol.

En el poema "Al vuelo" se retoma el "debate" sobre la relación entre forma y alma, entre lo interior y lo exterior en el arte, expresado en este y en otros textos de El libro blanco:

La forma es un pretexto, el alma todo!

La esencia es alma.-_Comprendéis mi norma?

Forma es materia, la materia lodo,

La esencia vida. ¡Desdeñad la forma!

La forma del poema como la forma de la estatua contienen el valor tan buscado, el alma del poema.

Finalmente, en la cuarta estrofa, se contrapone la visión de la estatua que anuncia la nueva raza con la que representa la máxima perfección femenina creada por el imaginario masculino, la venerable y magníficaVenus de Milo, oponiendo a la imaginada frialdad de la primera el calor potencial de la segunda:

-Frente a la Venus clásica de Milo

Sueño una estatua de mujer muy fea

Oponiendo al desnudo de la dea

Luz de virtudes y montañas de hilo!-

Nunca os atraiga el brillo del diamante

Más que la luz sangrienta de la llama:

Esta es vida, calor, pasión vibrante, 


\section{Aquella helado resplandor de escama!}

Es decir, que tanto la estatua como la musa son figuraciones que articulan las dificultades de enfrentar la estética en boga, y de actuar en contrapunto con las normas vigentes, sean éstas las de una mujer que es poeta o las del exterior, las miradas de la sociedad que juzga y apremia. La musa y la estatua constituyen de este modo dispositivos poéticos eficaces para estructurar una visión conjunta dentro de un mundo de voces masculinas con el que se desea contraponer una visión nueva de poeta joven. Es esta postura de confrontamiento junto a la visión aquí articulada de la estética por venir que preparan a Delmira Agustini para elaborar los poemas que escribió entre 1907 y 1914, Cantos de la mañana y Los cálices vacios. Su retrato de artista joven seguirá existiendo como proyecto en los libros posteriores, pero la visión y los temas de su poética se irán transformando a medida que su lenguaje poético y su proyecto acumulan intensidad de expresión y madurez de estilo. Leídas como propongo, la musa y la estatua son figuraciones de gran efectividad expresiva para la joven poeta Delmira Agustini , y a través de las cuales deja inscripta la plena conciencia de su vocación artística y del valor innovador de su poesía.

\section{BiBLIOGRAFÍA}

Achugar, Hugo. Poesia y sociedad. Montevideo: Marcha, 1985.

Agustini, Delmira. Poesías completas. Manuel Alvar, ed. Barcelona: Editorial Labor, 1971.

Poesías completas. Magdalena García Pinto, ed. Madrid: Editorial Cátedra, 1993.

Alvar, Manuel. "Prólogo". Delmira Agustini. Poesías Completas. Barcelona: Editorial Labor, 1971.

Bula Piriz, Roberto. "Estudio Preliminar". Julio Herrera y Reissig. Poesías completas y páginas en prosa. Madrid: Aguilar, 1961.

Cortazzo, Uruguay, coord. Delmira Agustini. Nuevas penetraciones críticas. Montevideo: Vintén Editor, 1996.

"Una hermenéutica machista. Delmira Agustini en la crítica de Alberto Zum Felde". Manuscrito provisto por el autor, sin publicar.

Dijskstra, Bram. Idols of Perversity. London: Oxford University Press, 1986.

García Pinto, Magdalena. "Delmira Agustini y los letrados uruguayos". Letteratura d'America XIII/49 (Roma, 1993) Número especial sobre literatura uruguaya. Hugo Achugar, ed. 45-64.

"Delmira Agustini y la crítica hispanoamericana". El puente de las palabras: Homenaje a David Lagmanovich. Inés Azar, ed. Washington, DC: Intermer 50. Serie Cultural, 1994. 221-234.

"Ensayo Introductorio". Delmira Agustini. Poesías Completas. Madrid: Ediciones Cátedra, 1993.

Giucci, Guillermo. Fiera de amor. La otra muerte de Delmira Agustini. Montevideo: Vintén Editor, 1995.

Herrera y Reissig, Julio. Poesías completas y páginas en prosa. Edición, estudio preliminar y notas de Roberto de Bula Piriz. Madrid: Aguilar, 1961. 
Ludmer, Josefina. "Las tretas del débil". La sarten por el mango. Patricia Gonzales y Eliana Ortega, eds. San Juan: Ediciones Huracán, 1984. 57-70.

Masiello, Francine. Entre civilización y barbarie. Mujer, nación y cultura literaria en la Argentina moderna. Buenos Aires: Beatriz Viterbo Editora, 1997.

Orgambide, Pedro. Un amor imprudente. Barcelona: Grupo editorial norma, 1944.

Prego Gadea, Omar. Delmira. Montevideo: Alfaguara, 1996.

Rama, Ángel. Rubén Darío yel modernismo. Caracas: Ediciones de la Universidad Central de Venezuela, 1970.

Las máscaras democráticas del modernismo. Montevideo: Fundación Ángel Rama, 1985.

Ramos, Julio. Desencuentros de la modernidad en América Latina. México: Fondo de Cultura Económica, 1989.

Rodríguez Monegal, Emir. Sexo y poesía en el 900 uruguayo. Los extraños destinos de Roberto y Delmira. Montevideo: Alfa, 1969.

Sabat Ercasty, Carlos. "Delmira y su mundo". Las Tertulias 11. Publicación de la Biblioteca Nacional de Montevideo, 1982.

Salaverri, Vicente. Una mujer inmolada. Montevideo: Cooperativa Editorial Pegaso, 1944.

Sarlo, Beatriz. Una modernidad periférica. Buenos Aires, 1920 y 1930. Buenos Aires: Nueva Visión, 1988.

Silva, Clara. Pasión y gloria de Delmira Agustini. Su vida y su obra. Buenos Aires: Editorial Losada, 1972.

Zum Felde, Alberto. "Delmira Agustini. Carta Abierta". El Día (Montevideo, 21 de febrero de 1914). 
